\title{
TIME SERIES ANALYSIS OF RADIO SIGNALS WET TROPOSPHERIC DELAYS FOR SHORT-TERM FORECAST
}

\author{
Zofia RZEPECKA ${ }^{1)}$, Jakub Zbigniew KALITA ${ }^{2)}$, \\ Katarzyna STEPNIAK ${ }^{1)}$ and Pawel WIELGOSZ ${ }^{1)}$ \\ ${ }^{1)}$ Faculty of Geodesy, Geospatial and Civil Engineering, University of Warmia and Mazury in Olsztyn, \\ Prawocheńskiego 15, 10-720 Olsztyn, Poland \\ ${ }^{2)}$ Department of Civil Engineering, Environmental Engineering and Geodesy, Koszalin University of Technology, \\ Śniadeckich 2, 75-453 Koszalin, Poland \\ *Corresponding author's e-mail: zofia.rzepecka@uwm.edu.pl
}

\begin{tabular}{|c|c|}
\hline ARTICLE INFO & ABSTRACT \\
\hline Article history: & \multirow{4}{*}{$\begin{array}{l}\text { The proposed short-term forecasting method bases on removing periodic signals basing on } \\
\text { frequency analysis and then using modern tools of time series analysis on residuals. For this } \\
\text { element the Auto-Regressive Integrated Moving Average forecasting model is used. The } \\
\text { practical realization contains the analysis of tropospheric data obtained from the Vienna } \\
\text { Mapping Function } 1 \text { service. The analysis contains time series data from four years (2010-2013) } \\
\text { and two permanent stations located in Central Europe region. For both stations two main signals: } \\
\text { annual and semiannual were removed using sine and cosine linear regression leaving residuals } \\
\text { that still do not act as a white noise processes. For each of the analysed data sets appropriate } \\
\text { parameters of the ARIMA model were evaluated and the accuracy of forecast values was } \\
\text { analysed. The residuals of these expanded processes are white, therefore the estimated ARMA } \\
\text { processes can be used for forecasting the future values. One-step forecasts based on the above } \\
\text { models are estimated to be within } \pm 2.5 \mathrm{~cm} \text { for } 80 \% \text { of confidence level and } \pm 3.8 \mathrm{~cm} \text { for } 95 \% \text { of } \\
\text { confidence. Unfortunately, its confidence level quickly drops down, falling down to within } \\
\pm 4 \mathrm{~cm} \text { for the fourth forecasted epoch (four epochs completes } 24 \mathrm{~h} \text { ), at } 80 \% \text { of level of } \\
\text { confidence. }\end{array}$} \\
\hline $\begin{array}{l}\text { Received } 2 \text { February } 2015 \\
\text { Accepted } 20 \text { June } 2015 \\
\text { Available online } 7 \text { September } 2015\end{array}$ & \\
\hline Keywords: & \\
\hline $\begin{array}{l}\text { Wet tropospheric delay } \\
\text { Time series analysis, forecast } \\
\text { ARMA } \\
\text { ARIMA } \\
\text { Power spectral density analysis } \\
\text { FFT } \\
\text { PPP }\end{array}$ & \\
\hline
\end{tabular}

\section{INTRODUCTION}

The radio signals used by existing Global Navigation Satellite Systems are delayed nondispersively while passing through the neutral atmosphere (Petit and Luzum, 2010). The delay is a function of refractive index along the geometric range between the receiver and the satellite. It can be divided into hydrostatic delay, caused by the dry gasses contained in the troposphere and stratosphere (Schüler, 2001; Hofmann-Wellenhof et al., 2008), and wet delay induced by the water vapor (Hopfield, 1969). In most precise applications, where single millimeters accuracy is concerned, the slant tropospheric delay is modeled using zenith hydrostatic $T_{z h}$ and wet delays $T_{z w}$ and horizontal delay gradients with respective elevation dependent mapping functions (Petit and Luzum, 2010). The proportion between zenith dry and wet delays is about $90 \%$ to $10 \%$. The delay increases with decrease of satellite elevation angle as given by Herrig (1992) for the dry and wet delays and as given by Chen and Herrig (1997) for gradient.

Knowing the total atmospheric pressure and station approximate latitude and height, a priori hydrostatic zenith delay may be accurately estimated (Davis, 1985; Petit and Luzum, 2010). Since the wet tropospheric delay a priori value precise prediction is currently unachievable, in most of the applications its residual is estimated as an additional parameter. In addition, for the most precise applications tropospheric horizontal gradients should be accounted for as the can reach or exceed value of $1 \mathrm{~mm}$ (Petit and Luzum, 2010).

Various models approximating pressure data in so called blind mode can be used to obtain the $T_{z h}$ value without the need of external data (Hopfield, 1969; Leandro et al., 2006; Böhm, 2007; Lagler et al., 2013). Similar approach exists for the wet component (RTCA-MOPS, 1999; Martellucci, 2012; Schüler, 2014; Böhm et al., 2014). The last mentioned model, GPT2w (Böhm et al., 2014) is the most accurate from the blind mode models. It utilizes the water vapor pressure, the mean temperature and water vapor decrease factor by using its mean values, annual and semi-annual amplitudes, giving mean bias of $-0.02 \mathrm{~cm}$ and mean RMS of $3.61 \mathrm{~cm}$. Other group of models uses either numerical weather models (Böhm, 2006a) or stream of local meteorological measurements taken in vicinity of the station, i.e. as done by Hadas et al. (2013) or Wielgosz et al. (2013), for estimation of the tropospheric zenith delay. In order to project the zenithal delay to particular elevation angle, mapping functions like: Niell Mapping Function (NMF; Niell, 1996), Global Mapping Function (GMF; Böhm et al., 2006b), Vienna Mapping Function (VMF1; Böhm et al., 2006a) are applied. Similar division of mapping functions to blind mode and functions that need additional data is present. 
a) LAMA staton - $T_{z w}$ for $\mathbf{2 0 1 0 - 2 0 1 3}$

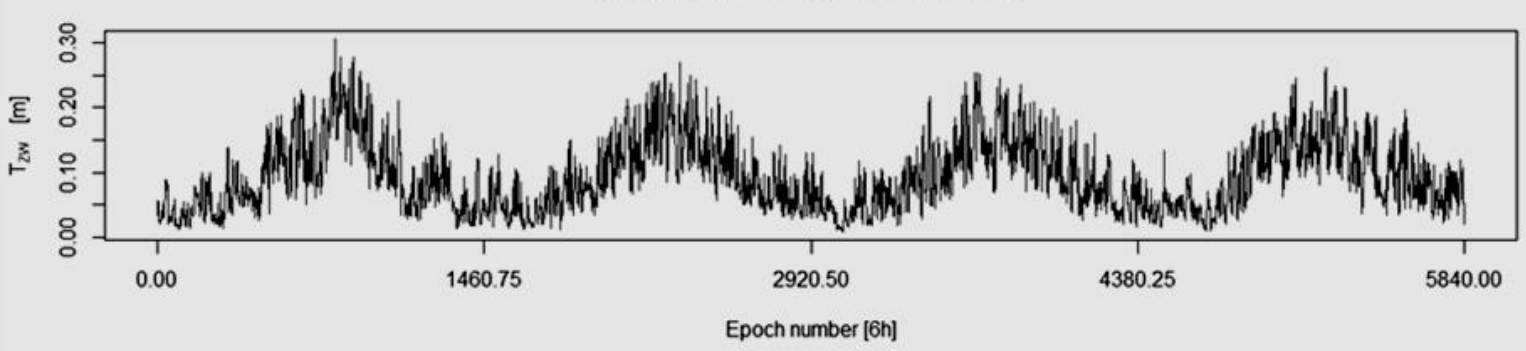

b) GOPE staton - $T_{z w}$ for $\mathbf{2 0 1 0 - 2 0 1 3}$

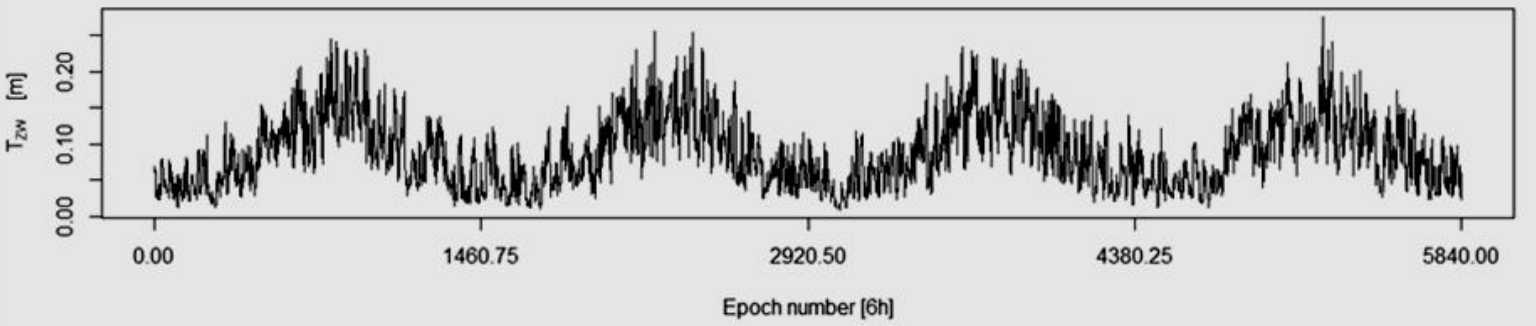

Fig. $1 T_{Z W}$ for LAMA (a) and GOPE (b) stations during 4 years, from Jan $1^{\text {st }} 2010$ till Dec $31^{\text {st }} 2013$.

The International GNSS Service (IGS) distributes final tropospheric zenith delay with the latency of 4 weeks and accuracy of $4 \mathrm{~mm}$ (http://igs.org/products). The temporal resolution is 2 hours, however, some services provide similar products with resolution of 5 min (Hackman and Byram, 2012). Due to their latency, these products can be used for verification of the models, but not for the real time positioning applications, especially that they are present for the IGS stations only. For real time positioning applications one of the blind mode, forecast of numerical weather models or weather data streams can be used.

The VMF1 forecast data base on the European Centre for Medium-Range Weather Forecast (ECMWF). Similar to the final VMF1 data, the forecast resolution is 6 hours. It is updated daily and extends for the next day. The product is available for the IGS sites as well as in the GRID form, enabling its global application (Böhm et al., 2008). The analysis of the forecast zenith delays and mapping parameter for both dry and wet components with regards to the final VMF1 parameters was already performed by Kalita et al. (2014), who reported the $1.2 \mathrm{~cm}$ standard deviation of the final VMF zenith wet delay. In addition, this study shows that the parameter quality was positively correlated with the amplitude of the delay and the length of the prediction.

The goal of the presented research was to model the wet tropospheric zenith delay using time series analysis tools. The dry tropospheric zenith delay $\left(T_{z}\right)$ is well predictable (Böhm et al., 2008). On the other hand, it is known that the wet part of the tropospheric delay $\left(T_{z w}\right)$ is not precisely predicted using weather models (Kalita et al., 2014). In addition, since the VMF1 forecast is based on the external weather data, the delay in providing those may lead to temporal unavailability of the required product. One of the scenario in such case would be switching to blind mode troposphere models (i.e. GPT $2 \mathrm{w}$ ), especially that the source code of the respective procedures is publicly available (http://ggosatm.hg.tuwien.ac.at/). However, the prediction that is based on the parameters provided by the service may give the higher accuracy than that of the blind mode.

Thus, an alternative forecast method that uses the wet zenith delays directly is presented further in this paper. The input data is treated as a time series and processed using the Auto-Regressive Integrated Moving Average (ARIMA) forecasting models.

\section{BASIC CHARACTERISTICS OF THE DATA}

Wet zenith delays from the years 2010-2013 were used in this analysis. Two IGS stations were chosen: LAMA (lat: 53⒌ 32"N, lon: $20^{\circ} 40^{\prime} 11^{\prime \prime} \mathrm{E}$, ellipsoidal elev.: $187.0 \mathrm{~m}$ ) and GOPE(lat:49 ${ }^{\circ} 54^{\prime} 49^{\prime \prime} \mathrm{N}$, lon: $14^{\circ} 47^{\prime} 08^{\prime \prime E}$, ellipsoidal elev.: $592.6 \mathrm{~m}$ ). The $T_{z w}$ values downloaded from the ggosatm server are given with time resolution of $6 \mathrm{~h}$ (4 values each day), giving $4 \times 365=1460$ values per year. Thus for the four years admitted for the study, there are $4 \times 1460=5840$ samples for each station. They start on MJD55197.00, for the purpose of the plots the epochs are numbered from 1 to 5840. Generally, the $T_{z w}$ values, for both the LAMA and GOPE stations, are between 0 and $30 \mathrm{~cm}$ (see Figs. 1a, 1b). Looking at the plots, one can easily notice annual changes and the apparent noisiness of the values. During winter times, the values are closer 

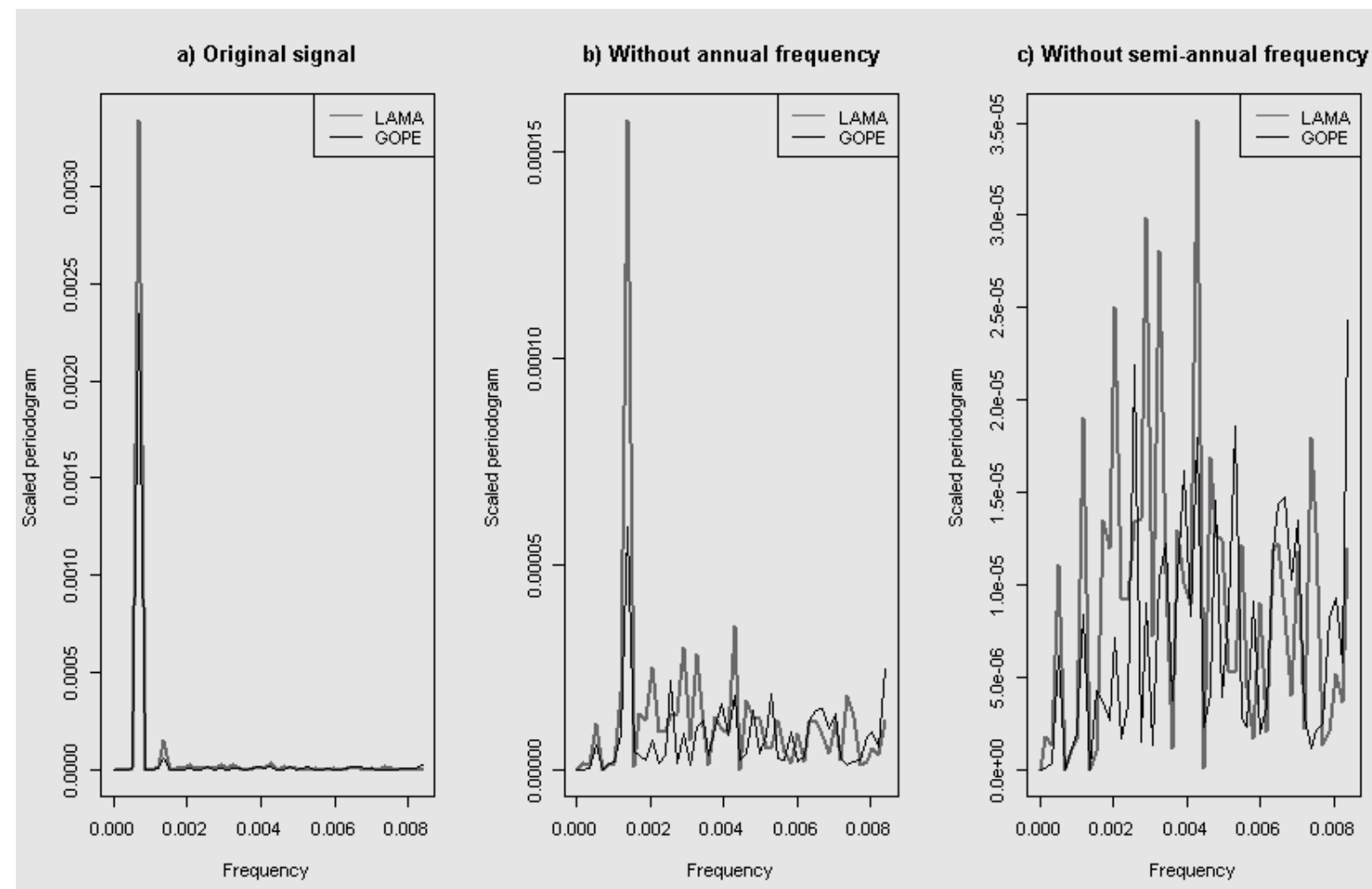

Fig. 2 Scaled periodograms of $T_{z w}$ (a) $T_{z w}$ without annual signal (b), $T_{z w}$ without semi-annual signal (c); notice change of scale.

Table 1 Basic statistics of the $T_{z w}$ values (20102013).

\begin{tabular}{lccrc}
\hline Station & $\begin{array}{c}\text { Minimum } \\
{[\mathrm{m}]}\end{array}$ & $\begin{array}{c}\text { Mean } \\
{[\mathrm{m}]}\end{array}$ & $\begin{array}{c}\text { Maximum } \\
{[\mathrm{m}]}\end{array}$ & $\begin{array}{c}\text { Standard } \\
\text { Deviation } \\
{[\mathrm{m}]}\end{array}$ \\
\hline GOPE & 0.009 & 0.088 & 0.277 & 0.046 \\
LAMA & 0.007 & 0.094 & 0.306 & 0.053 \\
\hline
\end{tabular}

to zero and calmer, while during summer periods they reach their maximum values.

Seasonal behavior of the data is obvious. It is possible to use periodogram analysis to find if the other frequencies are present in the series of $T_{z w}$ values. The periodogram values may be computed by means of the Fast Fourier Transform FFT (Shumway and Stoffer, 2011) as in Equation 1.

$P(\omega)=a b s\left(2 * \frac{F F T(\text { data })}{n}\right)^{2}$

The periodogram given in Figure $2 \mathrm{a}$ is based on the original series of the $T_{z w}$ values. The annual signal has the highest amplitude and is easily identified for both LAMA and GOPE series. After removing the signal of this frequency, using linear regression, also the semi-annual signal can be distinguished (Fig. 2b). After removing it, no other amplitudes dominate
(Fig. 2c). Since the annual and the semi-annual signals are distinctive, they were treated as a trend and removed from the series. For periodic data, it is natural to use sine with phase or sum of sine and cosine functions to detrend the data, remembering that the frequency of oscillation (annual and semi-annual) is known. In our case the one-year frequency is $\omega_{0}=\frac{2 \pi}{1460}$ and the half-year frequency is, with $t \in(1: 5840)$ in epochs (6h each). Linear regression that was performed is based in Equation 2:

$$
\begin{aligned}
x_{t}= & a_{0}+a_{1 c} \cos \left(\omega_{0} t\right)+a_{1 s} \sin \left(\omega_{0} t\right)+ \\
& +a_{2 c} \cos \left(2 \omega_{0} t\right)+a_{2 s} \sin \left(2 \omega_{0} t\right)
\end{aligned}
$$

where: $a_{1 s}, a_{1 c}, a_{2 s}, a_{2 c}$ are sine and cosine functions coefficients respectively, $a_{0} \mathrm{~s}$ the value of the intercept. The estimated coefficients are given in Table 2.

In further part of the study, only the residuals of the linear regression are dealt with (see Figs. 4a, 4b and Table 2) as they constitute a zero-mean process. In Figure 4 it can be seen that the residuals are in range of about $-10 \mathrm{~cm}$ to about $+15 \mathrm{~cm}$ for both LAMA and GOPE. Generally during winter the absolute values of the residuals are smaller, in summer they are more dispersed. In Figure 5, histograms of the residuals for LAMA and GOPE, 
Table 2 Linear regression results for the $T_{z w}$ series.

\begin{tabular}{|c|c|c|c|c|c|}
\hline \multicolumn{3}{|c|}{ LAMA } & \multicolumn{3}{|c|}{ GOPE } \\
\hline \multicolumn{6}{|c|}{ Residuals [m] } \\
\hline Min & Median & Max & Min & Median & Max \\
\hline-0.095 & -0.004 & 0.143 & -0.086 & -0.003 & 0.133 \\
\hline \multicolumn{6}{|c|}{ Coefficients [m] } \\
\hline Coefficient name & Estimate & Std. Error & Coefficient name & Estimate & Std. Error \\
\hline $\mathrm{a}_{0}$ & 0.0939 & 0.00044 & $\mathrm{a}_{0}$ & 0.0883 & 0.00040 \\
\hline$a_{1 c}$ & -0.0235 & 0.00062 & $a_{1 c}$ & -0.0195 & 0.00056 \\
\hline$a_{1 s}$ & -0.0528 & 0.00062 & $a_{1 s}$ & -0.0443 & 0.00056 \\
\hline$a_{2 c}$ & 0.0045 & 0.00062 & $a_{2 c}$ & 0.0034 & 0.00056 \\
\hline$a_{2 s}$ & 0.0117 & 0.00062 & $\mathrm{a}_{2 \mathrm{~s}}$ & 0.0069 & 0.00056 \\
\hline
\end{tabular}

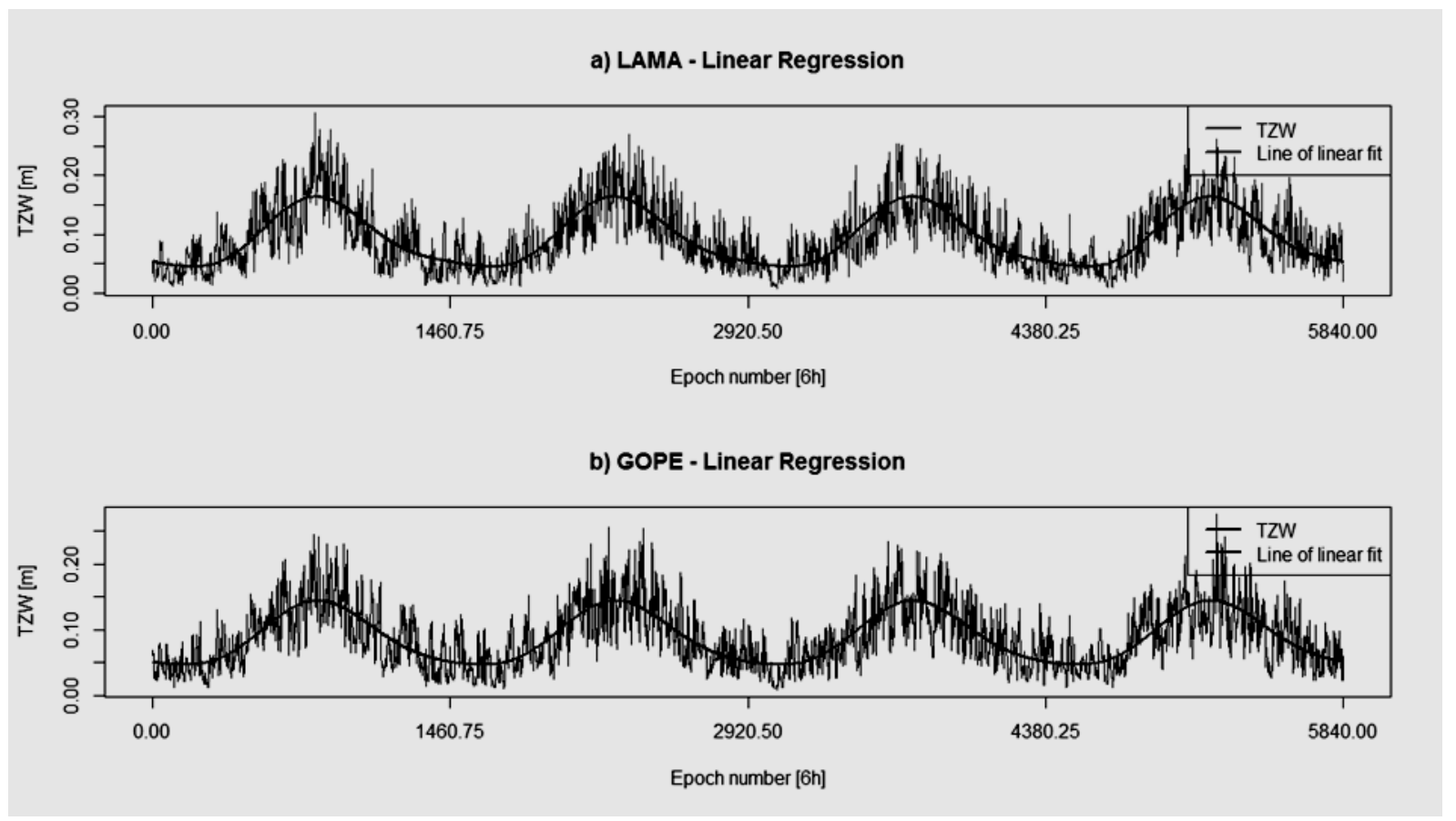

Fig. 3 Detrending the TZW data using linear regression with sines and cosines LAMA (a) and GOPE (b) stations.

grouped by $1 \mathrm{~cm}$, are presented. The histograms are slightly non-symmetric (which is also seen from the minimum and maximum values). There are more negative values close to zero (in -5 to $0 \mathrm{~cm}$ range) than positive ones ( 0 to plus $5 \mathrm{~cm}$ ), in case of both stations. On the other hand, for the bigger differences (absolute) the situation is reversed. Additionally, in Figure 5 we can see normal distribution density functions (zero-mean and standard deviations equal to standard deviations of the respective data) imposed on the histograms. Both LAMA and GOPE residuals data are slightly skewed and broken off at $-10 \mathrm{~cm}$ (LAMA) or at $-8 \mathrm{~cm}$ (GOPE) on the negative side of the horizontal axis, and reach about $+15 \mathrm{~cm}$ at the positive side of the axis.

In Figure 6 correlations at different lags (ACF), from 0 to 100 , are shown. ACF is an autocorrelation function, it is used here according to the definition given in (Shumway and Stoffer, 2011, p. 21). Lag means time separation of data for which we look for the ACF value. It can be seen that the residuals are not a white-noise processes, neither for LAMA nor for GOPE. The correlations are significant up to lags of about 30 (for LAMA residuals) and about 20 (for GOPE).

\section{FURTHER STUDYING OF THE RESIDUAL PROCESSES - ARMA MODELS AND FORECAST}

The most common methods of forecasting future behavior of time series include ARIMA (or ARMA) models, exponential smoothing and structural models (Hyndman and Athanasopoulos, 2013). In this study it was decided to apply the $\operatorname{ARIMA}(p, d, q)$ model that can be defined according to Equation 3. 
a) LAMA - Linear Regression Residuals

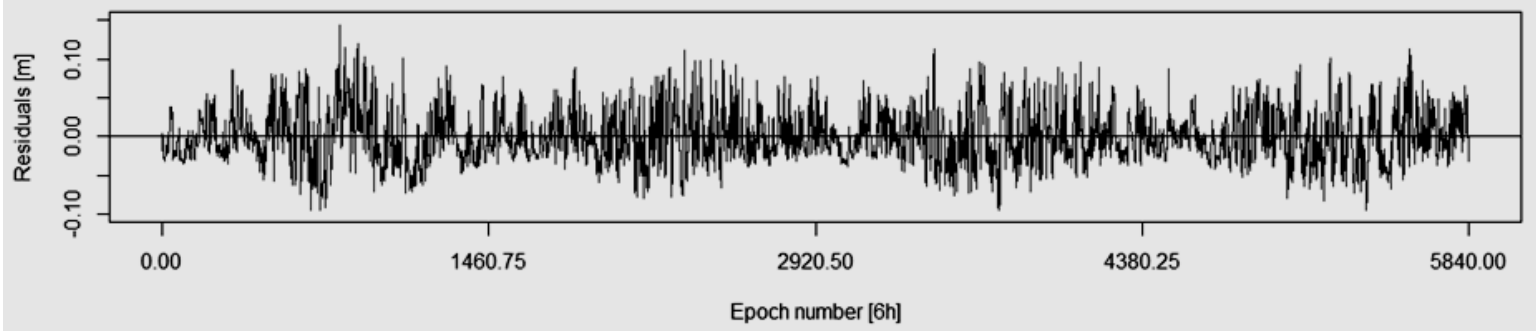

b) GOPE - Linear Regression Residuals

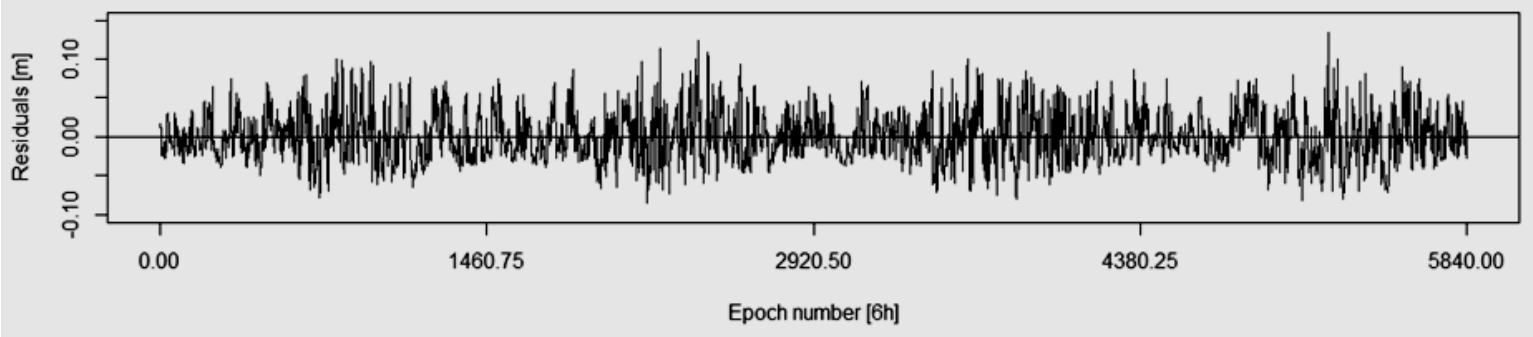

Fig. 4 Residuals of linear regression for LAMA (a) and GOPE (b) stations.

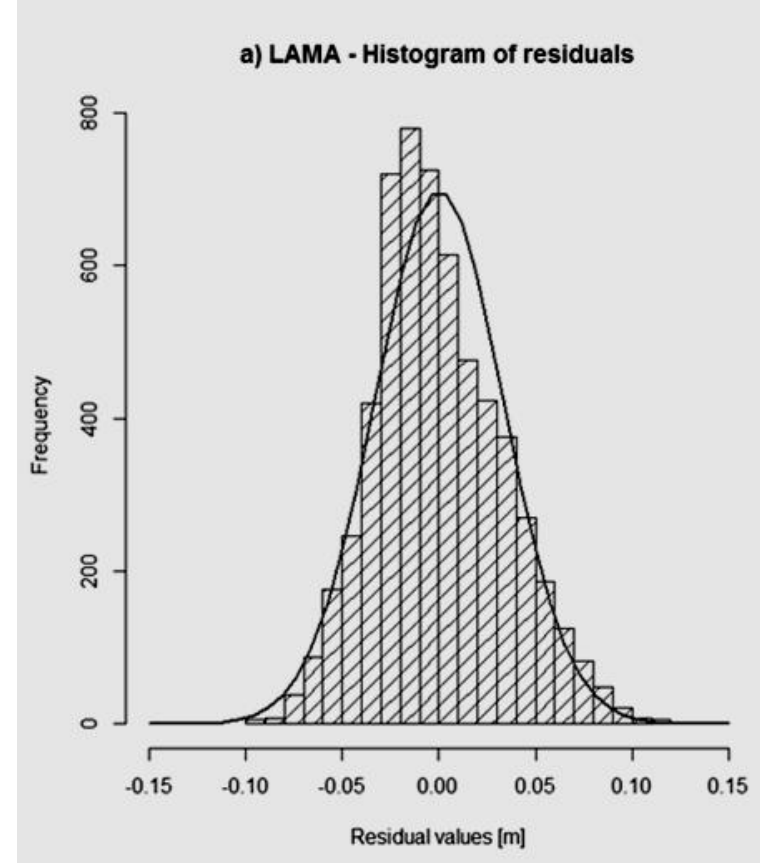

b) GOPE - Histogram of residuals

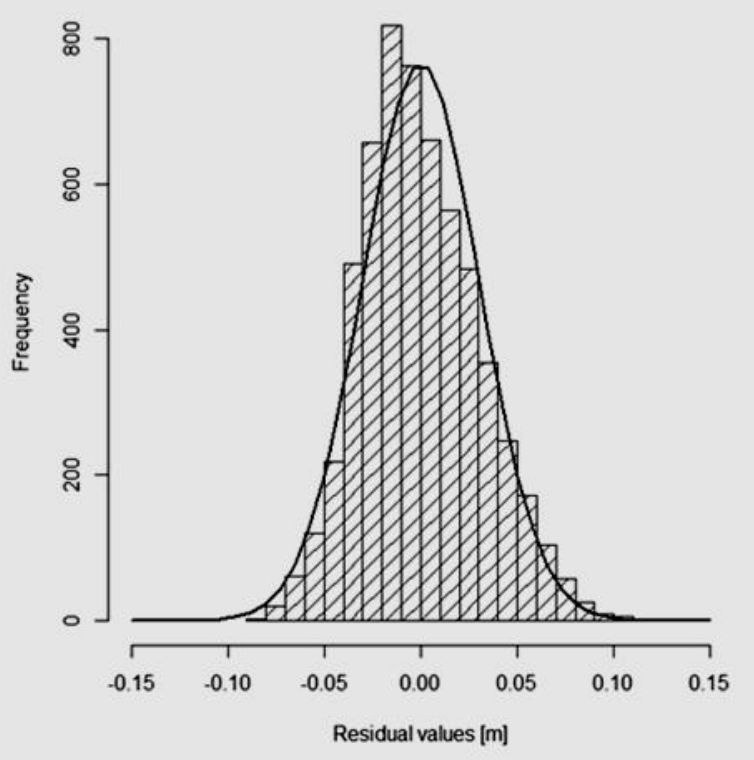

Fig. 5 Histograms of residuals of LAMA (a) and GOPE (b) together with a standard normal distributions.

$$
\left(1-\Phi_{1} B-\cdots \Phi_{p} B^{p}\right)(1-B)^{d} y_{t}=c+\left(1+\Theta_{1} B+\cdots \Theta_{q} B^{q}\right) e_{t}
$$

where: stands for backshift operator; $y_{t}$ is a predicted value of a series in moment $t$. The model comprises differencing $\left((1-B)^{d}\right)$, autoregression $\left(\Phi_{i}\right.$ is a coefficient for autoregressive element) and moving average $\left(\Theta_{i}\right.$ is a coefficient for moving average element).

It is well known that in an autoregressive model, we forecast the variable of interest using a linear combination of past values of the variable (AR part of the model). It is called AR(p) model with p number of past values of the time series used for the combination. On the other hand, a moving average (MA) model uses past forecast errors in a regression-like model. We refer to this as an $\operatorname{MA}(q)$ model when errors from q past epochs are used. In case we want to remove a trend, the differencing process may be used ( $\mathrm{d}$ times). When all the above models are combined, the full $\operatorname{ARIMA}(\mathrm{p}, \mathrm{d}, \mathrm{q})$ model is obtained (see Equation 3). In case of the residuals studied 
a) LAMA - Autocorrelation function for lags from 0 to 100

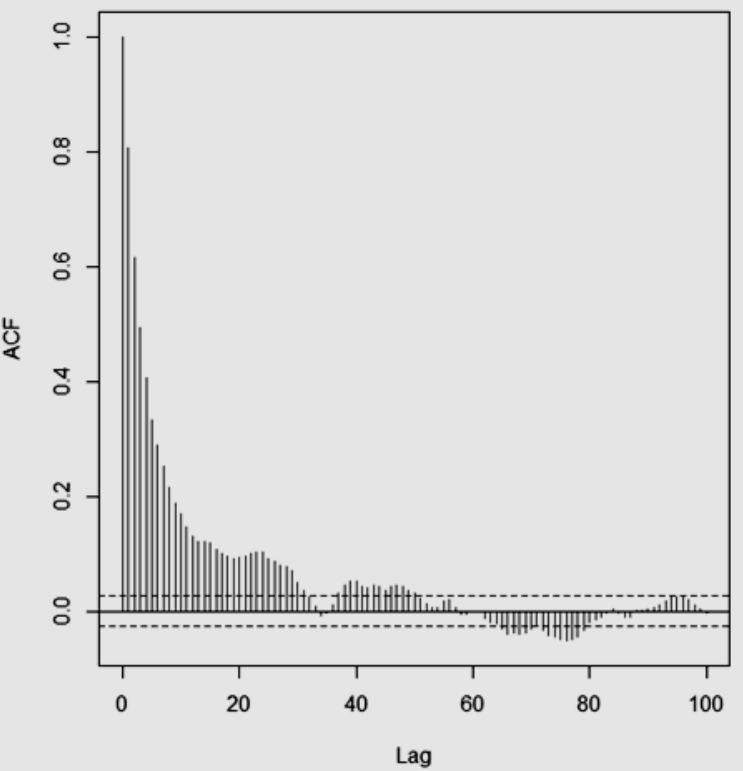

b) GOPE - Autocorrelation function for lags from 0 to 100

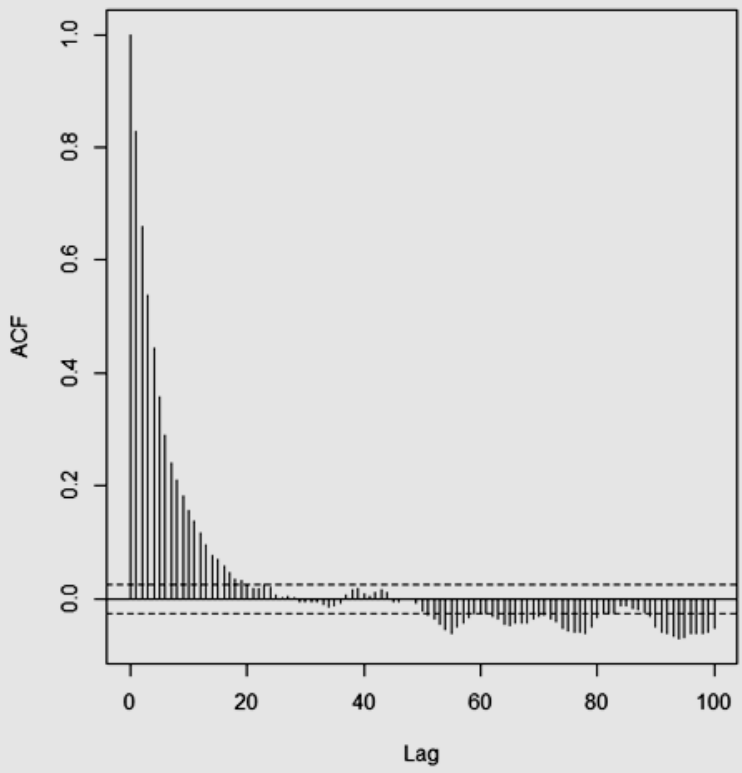

Fig. 6 Autocorrelation function values for lags from 0 to 100, for LAMA (a) and GOPE (b).

here, the trend was already removed from the data (see Section 2), thus $\mathrm{d}=0$. The remaining model may be referred as $\operatorname{ARIMA}(p, 0, q)$ model that is same as $\operatorname{ARMA}(p, q)$. From now on we use ARMA with respect to the derived models.

In this section we are going to determine the values of $p$ and $q$ for the residual data of LAMA and GOPE, together with the number of coefficients for the models. The determined values can then be used to forecast the future (not included to the time series) data.

It is known (Hyndman and Athanasopoulos, 2013) that the process is $\operatorname{ARMA}(p, 0)$ at $p>0$ if the ACF drops down exponentially or sinusoidally and the partial autocorrelation function (PACF) has a significant spike at $\mathrm{p}$, and that the process is $\operatorname{ARMA}(0, \mathrm{q})$ at $\mathrm{q}>0$ if the PACF drops down exponentially or sinusoidally and the ACF has a significant spike at q. In case of the residuals studied here, it can be assumed that ACFs drop down exponentially or sinusoidally, but there are not any spikes in PACF besides PACF for lag=1. Thus it can be suspected that both the series of LAMA and GOPE residuals are mixed AR and MA processes (ARMA(p,q), with neither $p$ nor $q$ are equal to 0 ).

To find out the values of $\mathrm{p}$ and $\mathrm{q}$, the $\mathrm{R}$ function auto.arima (Hyndman and Khandakar, 2008) was used. This function computes best ARIMA model according to indicated parameters (they can be either AIC, AICc or BIC). This function performs a search over possible models with small values of $\mathrm{p}$ and $\mathrm{q}$ (in case of non-stationary data it also performs differencing of the data, then $\mathrm{d} \neq 0$ would result). AIC means Akaike's Information Criterion, AICc stands for Bias Corrected AIC and BIC for Bayesian Information Criterion (Shumway and Stoffer, 2011, pp. 52-53). All these parameter definitions are based on the logarithm of maximum likelihood estimator. In respective formulas the logarithm term is then corrected by an appropriate combination of number of parameters $k$ of the tested model together with sample size $n$. When comparing models fitted by maximum likelihood to the same data, the smaller these parameters, the better the fit, therefore these parameters are used as criterions for choosing best models.

The search performed shows that the best results are obtained for $\operatorname{ARMA}(2,2)$ (or ARIMA(2,0,2)) for LAMA station, and ARMA(1,2) (or ARIMA $(1,0,2)$ ) for GOPE station. The summary of results, values of the coefficients in the ARMA models together with their standard errors are given in Table 3. All the standard errors are significantly smaller than the coefficients themselves, thus the results are reliable and statistically significant. Thus the residuals from the linear regression of Equation 2 with coefficients from Table 2 can further be modeled as in Equations 4 and 5.

$$
\begin{aligned}
& y_{t}(L A M A)=1.5373 \cdot y_{t-1}-0.5676 \cdot y_{t-2}-0.638 \cdot e_{t-1}-0.1770 \cdot e_{t-2}+e_{t} \\
& y_{t}(G O P E)=0.8146 \cdot y_{t-1}-0.0792 \cdot e_{t-1}-0.0445 \cdot e_{t-2}+e_{t}
\end{aligned}
$$

where $e_{t}, e_{t-1}, e_{t-2}$ are residuals of the process with standard deviation equal to $0.020 \mathrm{~m}$ (LAMA) and $0.017 \mathrm{~m}$ (GOPE). 
Table 3 Best ARMA model fitting results for the series of residuals (from the previous linear regression).

\begin{tabular}{cccccc}
\hline & LAMA & \multicolumn{5}{c}{ GOPE } \\
\hline AIC & AICc & BIC & AIC & AICc & BIC \\
-29371.47 & -29371.46 & -29338.11 & -30968.22 & -30968.22 & -30941.53 \\
& \multicolumn{5}{c}{ Coefficients $[\mathbf{m}]$} \\
\hline Coefficient name & Estimate & Std. Error & Coefficient name & Estimate & Std. Error \\
ar1 & 1.5373 & 0.1012 & ar1 & 0.8146 & 0.0115 \\
ar2 & -0.5676 & 0.0825 & ma1 & 0.0792 & 0.0178 \\
ma1 & -0.638 & 0.1005 & ma2 & -0.0445 & 0.0162 \\
ma2 & -0.177 & 0.0163 & - & - & - \\
\hline
\end{tabular}

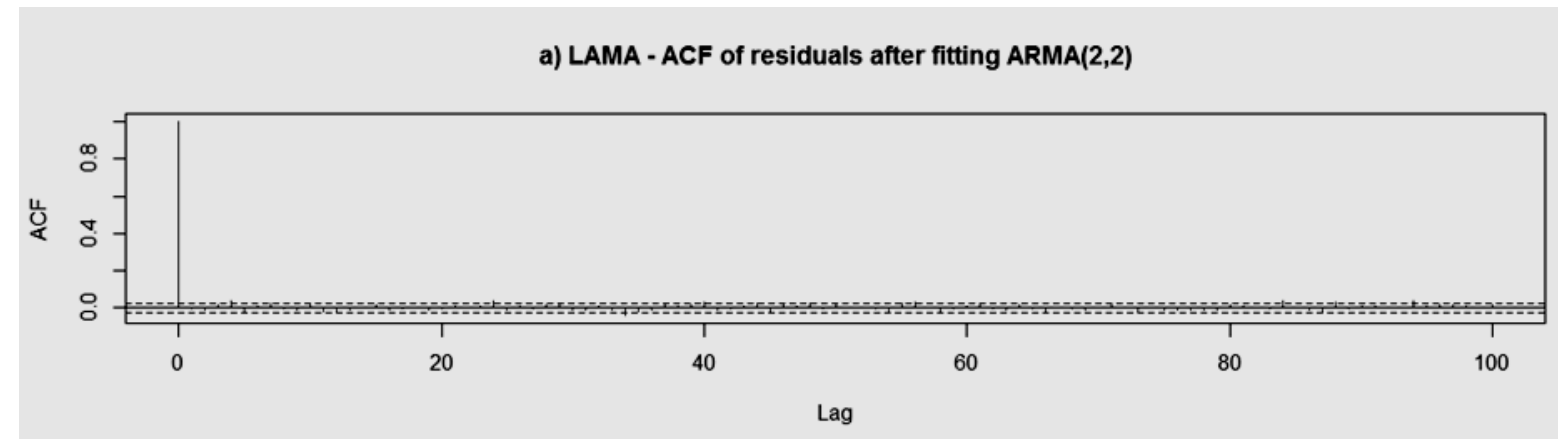

a) GOPE - ACF of residuals after fitting ARMA(1,2)

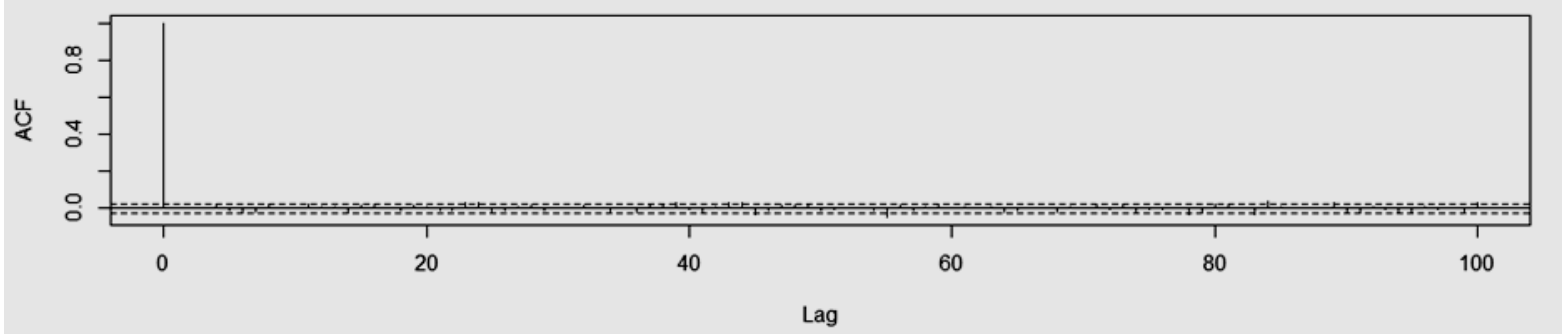

Fig. 7 Autocorrelation function of residuals after fitting $\operatorname{ARMA}(2,2)$ for LAMA (a) and $\operatorname{ARMA}(1,2)$ for GOPE (b); lags from 0 to 100 .

Before performing the forecasting procedure, it should be checked if the residuals remaining after ARMA fitting act as a white noise. Examining of the ACF values of the auto.arima residuals shows that they can be considered as white noise (see Fig. 7), therefore the estimated ARMA processes can be used for forecasting the future values (see Fig. 8).

Forecasting was performed taking advantage of function forecast (Hyndman and Khandakar, 2008). This function was used 5 times for both LAMA and GOPE stations, each time 4 future epoch values were predicted. The forecasting was performed on data to assure possibility of comparisons. Let us recall that there are 5840 values for each station. The first forecast is based on 5820 epochs and it predicts next 4 (epochs from 5821 to 5824). The second forecast is based on 5824 epochs and it predicts next 4 (epochs from 5825 to 5829), and so on. Graphic results of the forecast are given in Figure 8. The confidence levels are shown only for the fifth forecast to keep the plot readable. Computational summary of results of the fifth forecasts for LAMA and GOPE are presented in Table 4.

At confidence level of $80 \%$ the confidence intervals range from about $\pm 2.5 \mathrm{~cm}$ (for the first epoch predicted) to $\pm 3.8 \mathrm{~cm}$ (for the fourth epoch predicted) in case of LAMA, and from about $\pm 2.2 \mathrm{~cm}$ to about $\pm 3.5 \mathrm{~cm}$ in case of GOPE data. For $90 \%$ confidence level, the limit values increase respectively.

To check the forecast, the forecasted data were compared with the data provided by the ggosatmservice. Values computed from Equation 2 
a) LAMA - Forecasts from ARMA(2,2) with zero mean

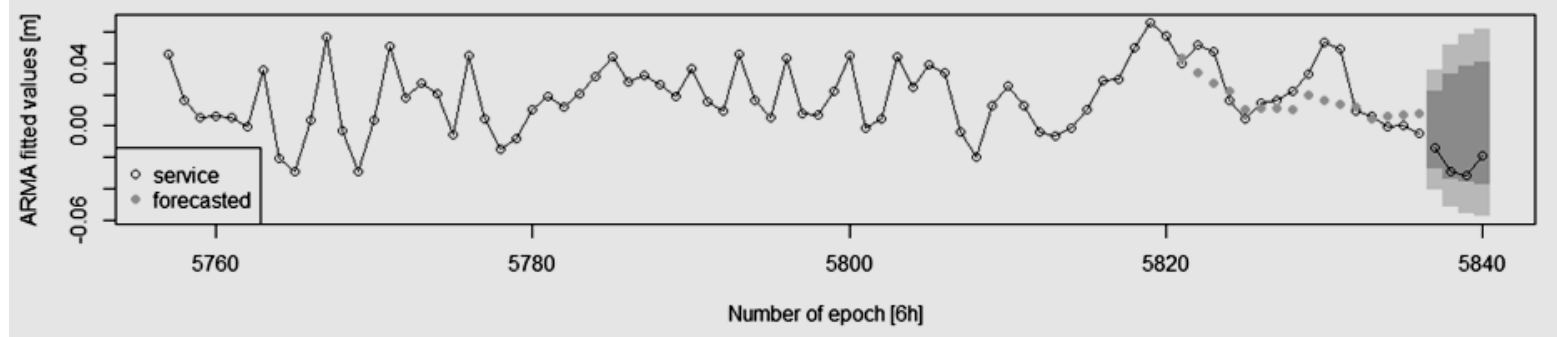

b) GOPE - Forecasts from ARMA(1,2) with zero mean

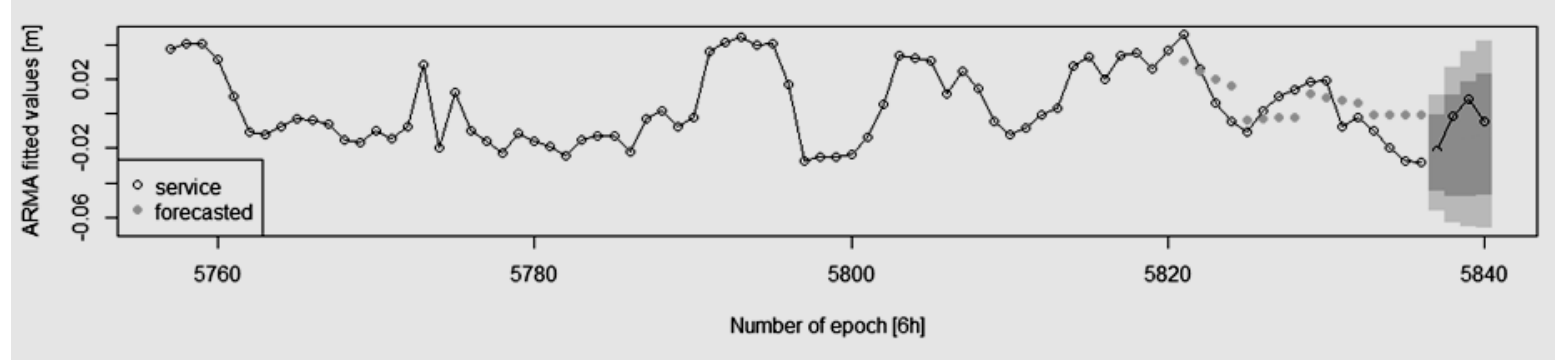

Fig. 8 Forecast results based on $\operatorname{ARMA}(2,2)$ for LAMA (a) and ARMA(1,2) for GOPE (b) for 4 epochs ahead.

Table 4 Forecast results based on the best ARMA.

\begin{tabular}{llllllllllll}
\hline \multicolumn{1}{c}{ LAMA } & \multicolumn{1}{c}{ GOPE } \\
\hline Point & Forecast & Lo 80 & Hi 80 & Lo 95 & Hi 95 & Point & Forecast & Lo 80 & Hi 80 & Lo 95 & Hi 95 \\
\hline 5837 & -0.0028 & -0.0278 & 0.0223 & -0.0411 & 0.0356 & 5837 & -0.0226 & -0.0445 & -0.0007 & -0.0561 & 0.0108 \\
5838 & -0.0002 & -0.0339 & 0.0334 & -0.0518 & 0.0513 & 5838 & -0.0182 & -0.0475 & 0.0111 & -0.0630 & 0.0267 \\
5839 & 0.0012 & -0.0361 & 0.0385 & -0.0559 & 0.0582 & 5839 & -0.0148 & -0.0477 & 0.0181 & -0.0652 & 0.0355 \\
5840 & 0.0019 & -0.0372 & 0.0410 & -0.0579 & 0.0617 & 5840 & -0.0121 & -0.0472 & 0.0230 & -0.0657 & 0.0416 \\
\hline
\end{tabular}

Table 5 Comparison between predicted and final values.

\begin{tabular}{ccccccccccr}
\hline Time & \multicolumn{4}{c}{ LAMA [m] } & \multicolumn{4}{c}{ GOPE [m] } \\
\cline { 2 - 12 }$[$ epoch] & Service & $X_{\mathrm{t}}$ & ARMA & Predict. & Differ. & Service & \multicolumn{1}{c}{$X_{\mathrm{t}}$} & ARMA & Predict. & Differ. \\
\hline 5821 & $\mathbf{0 . 0 9 4}$ & 0.054 & 0.044 & 0.098 & $\mathbf{- 0 . 0 0 4}$ & $\mathbf{0 . 0 9 8}$ & 0.052 & 0.031 & 0.083 & $\mathbf{0 . 0 1 5}$ \\
5822 & $\mathbf{0 . 1 0 5}$ & 0.054 & 0.034 & 0.088 & $\mathbf{0 . 0 1 8}$ & $\mathbf{0 . 0 7 8}$ & 0.052 & 0.024 & 0.076 & $\mathbf{0 . 0 0 1}$ \\
5823 & $\mathbf{0 . 1 0 1}$ & 0.054 & 0.027 & 0.081 & $\mathbf{0 . 0 2 0}$ & $\mathbf{0 . 0 5 8}$ & 0.052 & 0.020 & 0.072 & $\mathbf{- 0 . 0 1 4}$ \\
5824 & $\mathbf{0 . 0 7 0}$ & 0.054 & 0.022 & 0.076 & $\mathbf{- 0 . 0 0 6}$ & $\mathbf{0 . 0 4 7}$ & 0.052 & 0.016 & 0.068 & $\mathbf{- 0 . 0 2 1}$ \\
5825 & $\mathbf{0 . 0 5 9}$ & 0.054 & 0.011 & 0.065 & $\mathbf{- 0 . 0 0 6}$ & $\mathbf{0 . 0 4 1}$ & 0.052 & -0.004 & 0.048 & $\mathbf{- 0 . 0 0 7}$ \\
5826 & $\mathbf{0 . 0 6 8}$ & 0.054 & 0.011 & 0.065 & $\mathbf{0 . 0 0 3}$ & $\mathbf{0 . 0 5 3}$ & 0.052 & -0.003 & 0.049 & $\mathbf{0 . 0 0 4}$ \\
5827 & $\mathbf{0 . 0 7 0}$ & 0.054 & 0.011 & 0.065 & $\mathbf{0 . 0 0 5}$ & $\mathbf{0 . 0 6 1}$ & 0.052 & -0.002 & 0.049 & $\mathbf{0 . 0 1 2}$ \\
5828 & $\mathbf{0 . 0 7 6}$ & 0.054 & 0.011 & 0.064 & $\mathbf{0 . 0 1 2}$ & $\mathbf{0 . 0 6 6}$ & 0.052 & -0.002 & 0.050 & $\mathbf{0 . 0 1 6}$ \\
5829 & $\mathbf{0 . 0 8 7}$ & 0.054 & 0.020 & 0.074 & $\mathbf{0 . 0 1 3}$ & $\mathbf{0 . 0 7 0}$ & 0.052 & 0.012 & 0.063 & $\mathbf{0 . 0 0 7}$ \\
5830 & $\mathbf{0 . 1 0 7}$ & 0.053 & 0.016 & 0.070 & $\mathbf{0 . 0 3 7}$ & $\mathbf{0 . 0 7 0}$ & 0.051 & 0.009 & 0.061 & $\mathbf{0 . 0 1 0}$ \\
5831 & $\mathbf{0 . 1 0 3}$ & 0.053 & 0.014 & 0.067 & $\mathbf{0 . 0 3 5}$ & $\mathbf{0 . 0 4 4}$ & 0.051 & 0.007 & 0.059 & $\mathbf{- 0 . 0 1 5}$ \\
5832 & $\mathbf{0 . 0 6 3}$ & 0.053 & 0.012 & 0.066 & $\mathbf{- 0 . 0 0 3}$ & $\mathbf{0 . 0 4 9}$ & 0.051 & 0.006 & 0.057 & $\mathbf{- 0 . 0 0 9}$ \\
5833 & $\mathbf{0 . 0 6 0}$ & 0.053 & 0.004 & 0.058 & $\mathbf{0 . 0 0 2}$ & $\mathbf{0 . 0 4 2}$ & 0.051 & -0.001 & 0.051 & $\mathbf{- 0 . 0 0 9}$ \\
5834 & $\mathbf{0 . 0 5 2}$ & 0.053 & 0.006 & 0.060 & $\mathbf{- 0 . 0 0 7}$ & $\mathbf{0 . 0 3 2}$ & 0.051 & -0.001 & 0.051 & $\mathbf{- 0 . 0 1 9}$ \\
5835 & $\mathbf{0 . 0 5 3}$ & 0.053 & 0.007 & 0.060 & $\mathbf{- 0 . 0 0 7}$ & $\mathbf{0 . 0 2 4}$ & 0.051 & -0.001 & 0.051 & $\mathbf{- 0 . 0 2 6}$ \\
5836 & $\mathbf{0 . 0 4 8}$ & 0.053 & 0.008 & 0.061 & $\mathbf{- 0 . 0 1 2}$ & $\mathbf{0 . 0 2 3}$ & 0.051 & 0.000 & 0.051 & $\mathbf{- 0 . 0 2 7}$ \\
5837 & $\mathbf{0 . 0 3 9}$ & 0.053 & -0.003 & 0.050 & $\mathbf{- 0 . 0 1 1}$ & $\mathbf{0 . 0 3 0}$ & 0.051 & -0.023 & 0.028 & $\mathbf{0 . 0 0 2}$ \\
5838 & $\mathbf{0 . 0 2 4}$ & 0.053 & 0.000 & 0.053 & $\mathbf{- 0 . 0 2 9}$ & $\mathbf{0 . 0 4 9}$ & 0.051 & -0.018 & 0.033 & $\mathbf{0 . 0 1 6}$ \\
5839 & $\mathbf{0 . 0 2 1}$ & 0.053 & 0.001 & 0.054 & $\mathbf{- 0 . 0 3 3}$ & $\mathbf{0 . 0 6 0}$ & 0.051 & -0.015 & 0.036 & $\mathbf{0 . 0 2 4}$ \\
5840 & $\mathbf{0 . 0 3 4}$ & 0.053 & 0.002 & 0.055 & $\mathbf{- 0 . 0 2 1}$ & $\mathbf{0 . 0 4 7}$ & 0.051 & -0.012 & 0.039 & $\mathbf{0 . 0 0 8}$ \\
\hline
\end{tabular}


Table 6 Basic characteristics of differences between the ARMA predicted and final values of the $T_{z w}$.

\begin{tabular}{lcccc}
\hline Station & $\begin{array}{c}\text { Minimum } \\
{[\mathrm{m}]}\end{array}$ & $\begin{array}{c}\text { Mean } \\
{[\mathrm{m}]}\end{array}$ & $\begin{array}{c}\text { Maximum } \\
{[\mathrm{m}]}\end{array}$ & $\begin{array}{c}\text { Standard } \\
\text { Deviation } \\
{[\mathrm{m}]}\end{array}$ \\
\hline GOPE & -0.071 & -0.001 & 0.117 & 0.017 \\
LAMA & -0.083 & 0.000 & 0.112 & 0.020 \\
\hline
\end{tabular}

with coefficients taken from Table 2 for LAMA and GOPE (columns $x_{t}$ for LAMA and $x_{t}$ for GOPE) were added to the appropriate values of predictions (like in Table 4, columns ARMA) to obtain the full predictions (columns "Predict."). The latter were compared to the values from the service. Results were placed in columns "Differ.". All the values are given in meters.

It can be seen from the Table 5 that the forecast for GOPE station is quite precise, the differences range from $-27 \mathrm{~mm}$ to $24 \mathrm{~mm}$. In case of LAMA station, the forecast is not so accurate (differences from $-33 \mathrm{~mm}$ to $35 \mathrm{~mm}$ ), but still comparable with differences determined between the forecast and final $T_{z w}$ from Vienna service (Kalita et al., 2014). Respective mean values are $-1.5 \mathrm{~mm}$ and $0.3 \mathrm{~mm}$, standard deviations are 15 and $18 \mathrm{~mm}$. The root mean square of differences is equal to $24 \mathrm{~mm}$ for LAMA and $14 \mathrm{~mm}$ for GOPE stations.

Similar computations were performed for the whole year 2013. Basic characteristics of the differences between the forecasted and final values are given in Table 6. It is confirmed that the results obtained from ARMA one-day predictions are of comparable quality as those of the Vienna Service. It is confirmed that the results obtained from ARMA one-day predictions are of comparable quality as those of the Vienna Service.

\section{SUMMARY AND CONCLUSIONS}

In this paper, values of the wet tropospheric zenith delays of two chosen IGS stations, LAMA and GOPE, were analyzed. The data span covered 4 years: 2010-2013, being given each 6 hours. Both stations are located in Central Europe, LAMA in the northeastern part of Poland, with $\mathrm{h}=187 \mathrm{~m}$, and GOPE in Sudety Mountains, with $\mathrm{h}=593 \mathrm{~m}$ of ellipsoidal height. The $T_{z w}$ delays studied in this paper range from 0 to about $30 \mathrm{~cm}$, with standard deviation of about $5 \mathrm{~cm}$. The GOPE is slightly less dispersed than LAMA. Tropospheric zenithal delay of both the stations shows strong seasonability. On the basis of periodogram analysis it was found that there are two main frequencies buried in the data: the annual (the biggest) and the semi-annual (considerable smaller than the annual, but still significantly bigger than the others). Therefore it was decided to present the main signal taking advantage of the linear regression with sine and cosine functions of the annual (1/1460) and semi-annual (2/1460) frequencies. The coefficients for resulting signals are given in Table 2 . These signals can be used for prediction of tropospheric zenith delay values contained in these main signals. The remaining residuals of the above approximation range from $-10 \mathrm{~cm}$ to $+10 \mathrm{~cm}$, their mean is zero, and their standard deviations are about $3 \mathrm{~cm}$. Analysis of residual histograms indicate small shift from the normal distribution for these residuals.

In the next step, the residuals were analyzed, showing that they are not white noise processes. From autocorrelation functions for different lags it was found that the correlations are significant up to lags of about 30 (for LAMA residuals) and about 20 (for GOPE). Therefore, trying to describe how the residuals behave, preparing this process to the forecasting procedure, the residuals of LAMA and GOPE were modeled as ARMA processes. Analysis of indicators AIC, AICc, BIC suggested processes $\operatorname{ARMA}(2,2)$ for LAMA and $\operatorname{ARMA}(1,3)$ for GOPE. Having the $\mathrm{p}$ and $\mathrm{q}$ determined together with the values of appropriate coefficients (Table 3), the models of the residual processes can be written in the form of Equations 4 and 5. Thus, at this stage of the analysis, the $T_{z w}$ signals can be modelled as a sum of linear regressions functions (Equation 2 and Table 2) and the models of residual processes:

$$
\begin{aligned}
& T_{z w_{t}}(L A M A)=x_{t}(L A M A)+y_{t}(L A M A), \\
& T_{z w_{t}}(G O P E)=x_{t}(G O P E)+y_{t}(G O P E)
\end{aligned}
$$

Residuals of these expanded processes are white, therefore the estimated ARMA processes can be used for forecasting the future values. One-step forecasts based on the above models are estimated to be within $\pm 2.5 \mathrm{~cm}$ for $80 \%$ of confidence level and $\pm 3.8 \mathrm{~cm}$ for $95 \%$ of confidence. Unfortunately, its confidence level quickly drops down, falling down to within $\pm 4 \mathrm{~cm}$ for the fourth forecasted epoch (four epochs completes $24 \mathrm{~h}$ ), at $80 \%$ of level of confidence. Basing on the analysis performed for the whole year 2013 it is confirmed that the results obtained from ARMA one-day predictions are of comparable quality as those of the Vienna Service.

The approach proposed in this paper bases on data gathered from the VMF1 service for particular permanent stations. However, the gridded data are also available what enables similar quality (Böhm et al., 2008), and thus this approach enables global coverage. Similar approach of considering annual and semiannual components is used in recent tropospheric prediction models (i.e. Böhm et al., 2014). The GPT2w model enables comparable quality of wet component prediction in blind mode. Not requiring additional data gives significant advantage over models based on the VMF1 data as the one in this paper. However, as the model proposed in this paper deals with the residuals after removing the annual and 
semi-annual periodical signals, further benefits may arise. The model is dependent on values several recent past data samples, and thus it may adjust better to changes not handled in annual and semiannual signals like a non-cyclic changes in the wet part of the troposphere. Taking into consideration the fact that the parameters of VMF1 service may be biased, further detailed studies comparing the quality of both should be performed.

\section{REFERENCES}

Böhm, J., Werl, B. and Schuh, H.: 2006a, Troposphere mapping functions for GPS and VLBI from ECMWF operational analysis data. Journal of Geophysical Research, 111, No. B02406. DOI: $10.1029 / 2005 J B 003629$

Böhm, J., Niell, A., Tregoning, P. and Schuh, H.: 2006b, Global Mapping Function (GMF): A new empirical mapping function based on numerical weather model data. Geophysical Research Letters, 33, No.L07304. DOI: 10.1029/2005GL02554

Böhm. J., Heinkelmann, R. and Schuh, H.: 2007, Short note: a global model of pressure and temperature for geodetic applications. Journal of Geodesy, 81, No. 10, 679-683. DOI: 10.1007/s00190-007-0135-3

Böhm, J., Kouba, J. and Schuh, H.: 2008, Forecast Vienna Mapping Functions 1 for real-time analysis of space geodetic observations. Journal of Geodesy, 83, No. 5, 397-401. DOI: 10.1007/s00190-008-0216-y

Böhm, J., Möller, G., Schindelegger, M., Pain, G. and Weber, R.: 2014, Development of an improved empirical model for slant delays in the troposphere (GPT2w). GPS Sollutions, 19, No. 3, 433-441. DOI: 10.1007/s10291-014-0403-7

Chen, G. and Herring, T.A.: 1997, Effects of atmospheric azimuthal asymmerty on the analysis of space geodetic data. Journal of Geophysical Research, 102, No. B9, 20489-20502. DOI: 10.1029/97JB01739

Davis, J.L., Herring, T.A., Shapiro, I.I., Rogers, A.E.E. and Elgered, G.: 1985, Geodesy by radio interferometry: effects of atmospheric modeling errors on estimates of baseline length. Radio Science, 20, No. 6, 1593-1607. DOI: 10.1029/RS020i006p01593

Hackman, C. and Byram, S.: 2012, IGS Troposphere Working Group. In: Dach, R. and Jean, Y. (Eds.): International GNSS Service-Technical Report 2012, 195-199.

Hadas, T., Kaplon, J., Bosy, J., Sierny, J. and Wilgan, K.: 2013, Near-real-time regional troposphere models for the GNSS precise point positioning technique. Measurement Science and Technology, 24 No. 5. DOI:10.1088/0957-0233/24/5/055003

Herring, T.A.: 1992, Modelling atmospheric delays in the analysis of space geodetic data. In: de Munck, J.C. and Spoelstra, T.A.T. (Eds.), Proceedings of the symposium refraction of transatmospheric signals in geodesy. Hague, 157-164.

Hofmann-Wellenhof, B., Lichtenegger, H. and Wasle, E.: 2008, GNSS - Global Navigation Satellite Systems. Wien, Springer-Verlag, 516pp.

Hopfield, H.S.: 1969, Two-quartic tropospheric refractivity profile for correcting satellite data. Journal of Geophysical Research, 74, No. 18, 4487-4499. DOI: $10.1029 / \mathrm{JC} 074 \mathrm{i} 018 \mathrm{p} 04487$
Hyndman, R.J. and Athanasopoulos, G.: 2013, Forecasting: principles and practice. (http://otexts.org/fpp/ Accessed on 3 Jan. 2015)

Hyndman, R.J. and Khandakar, Y.: 2008, Automatic time series forecasting: The forecast package for R. Journal of Statistical Software, 26, No. 3, 1-22. (http://ideas.repec.org/a/jss/jstsof/27i03.html).

Petit, G. and Luzum, B.: 2010, IERS Conventions (IERS Technical Note; 36), Frankfurt am Main. Verlag des Bundesamts für Kartographie und Geodäsie, 179 pp.

Kalita, J.Z., Rzepecka, Z. and Krzan, G.: 2014, Evaluation of the possibility of using the predicted tropospheric delays in real time GNSS positioning. Artificial Satellites, 49, No. 4, 179-189. DOI: 10.2478/arsa-2014-0014

Lagler, K., Schindelegger, M., Böhm, J., Krásná, H. and Nilsson, T.: 2013, GPT2: empirical slant delay model for radio space geodetic techniques. Geophysical Research Letters, 40, No. 6, 1069-1073. DOI: $10.1002 /$ grl.50288

Leandro, R.F., Santos, M.C. and Langley, R.B.: 2006, UNB neutral atmosphere models, development and performance. In: Proceedings ION NTM 2006, Institute of Navigation, Monterey, California, 564573, 18-20 January.

Martellucci, A.: 2012, Galileo reference troposphere model for the user receiver. ESA-APPNG-REF/00621-AM v2.7.

Niell, A.: 1996, Global mapping functions for the atmosphere delay at radio wavelengths. Journal of Geophysical Research, 101, No. B2, 3227-3246. DOI: $10.1029 / 95 J B 03048$

RTCA-MOPS: 1999, Minimum operational standards for global positioning system/wide area augmentation system airborne equipment. October 6, RTCA/DO229 B. RTCA Inc., Washington, USA.

Schüler, T.: 2001, On Ground-Based GPS Tropospheric Delay Estimation, $\mathrm{PhD}$ Thesis, Universität der Bundeswehr München.

Schüler, T.: 2014, The TropGrid2 standard tropospheric correction model. GPS Solutions, 18, No. 1, 123-131. DOI: $10.1007 / \mathrm{s} 10291-013-0316-\mathrm{x}$

Shumway, R.H. and Stoffer, D.S.: 2011, Time Series Analysis and Its Applications, Springer New York Dordrecht Heidelberg London.

Wielgosz, P., Krukowska, M., Paziewski, J., KrypiakGregorczyk, A., Stępniak, K., Kapłon, J., Sierny, J., Hadaś, T. and Bosy, J.: 2013, Performance of ZTD models derived in near real-time from GBAS and meteorological data in GPS fast-static positioning. Measurement Science and Technology, 24, No. 12. DOI: $10.1088 / 0957-0233 / 24 / 12 / 125802$ 